\title{
Open Access Week: Library Strategies for Advancing Change
}

\author{
Jamaica Jones, Special Projects Librarian, \\ National Center for Atmospheric Research \\ Andrew Waller, Licensing and Negotiations Librarian \\ and Open Access Librarian, University of Calgary
} with Jennifer McLennan, Director of Programs and Operations, SPARC

Over the past several years, libraries have strategically brought to bear the power of a global awareness event we call "Open Access Week" to advance real, policy-driven scholarly communication change on campus. Initiated by students and marked by just a few dozen campuses in 2007, Open Access Week has evolved into a truly global phenomenon thanks to the ongoing leadership of the library community. Not simply an awareness-raising exercise, librarians have made Open Access Week a platform for advancing specific policy changes on research sharing and dissemination, including institution-wide commitments to open access. In anticipation of Open Access Week 2010 (October 18-24) and beginning to formulate local strategies, SPARC has invited two leading participants from 2009 to share in the following two articles how the event helped them to advance open access to research. For more details about plans and developments around Open Access Week 2010, visit http://www.openaccessweek.org/ or contact Jennifer McLennan jennifer@arl.org.

\section{一Jennifer McLennan}

\section{University Corporation for Atmospheric Research}

\section{Jamaica Jones}

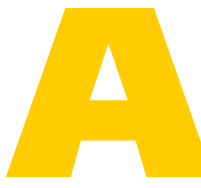

$\mathrm{t}$ the University Corporation for Atmospheric Research (UCAR), Open Access Week 2009 provided an opportunity to raise awareness about openness in scientific research. UCAR is sponsored by the National Science Foundation (NSF) to manage the National Center for Atmospheric Research (NCAR), a Federally Funded Research and 
Development Center (FFRDC) that provides the facilities, tools, and models needed to advance science across the atmospheric and geoscience community. NCAR employs several hundred scientists, whose work and research are supported by the NCAR Library, a small, specialized library committed to the facilitation and stewardship of NCAR research.

Together, NCAR and UCAR share a mission of supporting research across the broad atmospheric and geoscience community. That community is comprised of over 150 UCAR Member and Affiliate institutions, each of which offers advanced degrees in related scientific disciplines. Many UCAR Members operate under budgets that render access to the top journals in the field impossible. For this reason and for several decades, Members have asked the NCAR Library to provide them with access to scholarship written by UCAR researchers. While the NCAR Library is fortunate enough to have subscriptions to most of the journals publishing this scholarship, we have been unable to provide access to UCAR scholarship outside of our own institution, owing to the terms of our subscription and publishing agreements. Motivated by these challenges, the NCAR Library began in early 2009 to advocate for the adoption of an open access mandate across UCAR. After only a few months, this policy was passed, making it the first to be adopted by any FFRDC.

Open Access Week 2009 came on the heels of that achievement. Because UCAR is a highly decentralized, busy place, we chose to celebrate "Open Access Day" rather than "Open Access Week," and opted to plan one central event. We hosted a panel discussion between George Strawn, then the Chief Information Officer of the NSF, who spoke about the role of the federal government in fostering and funding major technological innovations, and John Wilbanks, Vice President of Science at Creative Commons, who presented the merging of these innovations and communication technologies as an inevitable, necessary step in the advancement of science. Introduced by Rick Anthes, President of UCAR, and moderated by Richard Katz, Director of the EDUCAUSE Center for Applied Research (ECAR), co-sponsor of the day's events, the discussion was attended by a robust crowd of lab and department directors, UCAR governance, scientists, and administrators. Conversation following the panel discussion was lively, reflecting a high level of interest and engagement in the material presented.

In planning Open Access Day 2009, our hope for the outcome of our celebration was simply to raise awareness about the potential of open access to transform scientific communication. Judging by the diverse audience the discussion attracted, 
and the thoughtful conversation it inspired, the event was quite successful. We would therefore like to offer the following recommendations to other institutions or departments planning Open Access Week activities in the future:

- Make it relevant. Well-structured, relevant conversations are more engaging for everyone involved.

- Draw on your institution's mission statement. Tying the discussion to your institution's mission will help to ensure this relevance, and will also help secure buy-in and interest from your senior management.

- Create connections. Prior to the 2009 panel discussion, we arranged for John Wilbanks to meet with some of our most prominent scientists, allowing him to understand the culture and concerns of UCAR, and helping the scientists to recognize how advances in open access can extend the impact of their research.

- Meet your audience where they are, physically as well as intellectually.

- Plan early, schedule early. This will be especially important if your institution is hoping to bring in a speaker. Once you know the date, ask people to hold it, and let them know to look forward to future updates.

- Give them stuff, but also give them information. While you are handing out buttons and T-shirts, do not miss the opportunity to educate and inform your audience about the importance of open access in scholarly publishing. This is a particularly valuable approach for institutions planning their first Open Access Week, and will help you stay within your budget.

At the time this article is being written, plans for UCAR's celebration of Open Access Week 2010 remain underway. We will certainly use the opportunity to celebrate the launch of UCAR's open access repository, OpenSky (scheduled for September 2010), and look forward to building on the momentum of last year's successes.

(C) 2010 Jamaica Jones

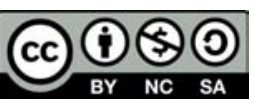

This article is licensed under a Creative Commons Attribution-NoncommercialShare Alike 3.0 United States License. To view a copy of this license, visit http: / / creativecommons.org/licenses/by-nc-sa/3.0/us/. 


\section{University of Calgary}

\section{Andrew Waller}

ed by the Libraries and Cultural Resources (LCR) unit, Open Access (OA) Week 2009 was a successful and enjoyable experience at the University of Calgary, a large, publicly funded Canadian university with close to 30,000 students and a medical school. We used OA Week to further spread the word about open access on campus as well as increase the profile of our suite of OA-related endeavors. These endeavors include an institutional repository, an authors fund, a digitization center, OA journals in the University of Calgary Press, and an OA mandate for the academic staff in LCR to widely and openly disseminate their own scholarly activities. The positive nature of OA Week 2009 at the University of Calgary can be attributed to two elements: we planned well and we held a wide variety of activities during the week that produced noticeable results.

\section{Planning}

Led by a core team comprised of staff from a variety of LCR departments, our planning process consisted of several elements:

- We did our research. We did not take part in OA Week 2008 but we made sure we talked with institutions that did do something that year and we learned from them (what worked, what did not, etc.).

- We aimed big. As we are fairly well established in terms of OA activities, we wanted an OA Week program that complemented our progress. In addition, as we had not participated in the 2007 and 2008 OA Weeks, we had some catching up to do, so to speak. Not all of our initial plans for OA Week 2009 came to fruition but many did.

- LCR administration was on our side. Our director, Tom Hickerson, was very supportive, had plenty of ideas as to what we could do, and he gave us a budget of approximately $\$ 5,000$ (CAN).

- We reached out to LCR colleagues. A core team of LCR staff planned our OA Week program but also put the word out to everyone in LCR and drew on help from these colleagues, in both big and small ways.

- We reached out to campus supporters outside of LCR. Rose Goldstein, 
the university's Vice-President (Research) has been supportive of our OA efforts over time and continued this support during OA Week, including her introduction of Leslie Chan, from Bioline International, who was the keynote speaker. Our Students' Union (SU) also supported OA Week by co-sponsoring Chan's presentation.

\section{Activities}

We carried out many activities during OA Week 2009. Some of the key activities included:

- We employed the visual element. The OA Week colors and graphics are striking and people seem to really like them. We incorporated the OA Week images wherever we placed a display or a banner or posters.

- We had an OA Week element in every library location. Every branch had something OA-related for the entire week, ranging from a small static display to a large, staffed desk.

- We worked with the media. We communicated with the media both on and off campus to promote OA and OA Week issues.

- We gave away stuff. People like free stuff (especially orange T-shirts). Giving away OA tchotchkes opens the door to conversations about open access and related issues.

\section{Some Results}

Anecdotally, our OA Week 2009 activities brought about more knowledge of $\mathrm{OA}$ and $\mathrm{OA}$ issues at the University of Calgary. The week's events included strong promotion of the OA projects we have at the university, all of which have continued to attract increasing interest since last October; for instance, our Open Access Authors Fund has funded over 60 articles since OA Week and our institutional repository is the second largest university repository in Canada.

Not long after OA Week 2009, the legislative assembly of the University of Calgary Students' Union passed a resolution in support of open access. They are one of the few undergraduate student bodies to have taken such a step.

Lastly, OA Week 2009 gave us good momentum for OA Week 2010. 
(C) 2010 Andrew Waller

\section{(c) (i) $\$$}

This article is licensed under a Creative Commons Attribution-NoncommercialShare Alike 3.0 United States License. To view a copy of this license, visit http: / / creativecommons.org/licenses/by-nc-sa/3.0/us/.

To cite this article: Jamaica Jones, Andrew Waller, Jennifer McLennan. “Open Access Week: Library Strategies for Advancing Change." Research Library Issues: A Bimonthly Report from ARL, CNI, and SPARC, no. 270 (June 2010): 21-26. http: / / www.arl.org/resources/pubs/rli/archive/rli270.shtml. 